\title{
EDITORIAL
}

\section{La Instrumentalización de los psiquiatras: El poder que no queremos.}

\section{Eudoxia Gay Pamos}

Desde el inicio de esta legislatura se está produciendo en todo el Estado una disminución de la inversión en los servicios públicos en general y en los sanitarios en particular, afectando de lleno a la atención a la Salud Mental.

Además se están proponiendo modificaciones legislativas que merman el derecho a la salud, como la exclusión de la asistencia sanitaria de determinados colectivos, o tener que contribuir económicamente en el sostenimiento de los tratamientos, sobre todo en personas con enfermedades crónicas y escasos recursos económicos.

En Salud Mental, asistimos a otras actuaciones que nos devuelven a situaciones que creíamos ya superadas, al menos legislativamente. Vuelve a estigmatizarse a los ciudadanos con problemas mentales, marcándolos con disposiciones y leyes específicas como si éstos necesitasen un estatus especial que requiere medidas y consideraciones más allá de las necesarias para cualquier ciudadano.

El rol profesional de los psiquiatras se utiliza para coartar los derechos de las mujeres, mediante la denominada sarcásticamente "Ley Orgánica de la Protección de la Vida del concebido y no nacido y de los Derechos de la Mujer Embarazada" contra la que la AEN-profesionales de la Salud Mental, llevamos varios meses posicionándonos y debatiendo en diferentes foros. Como Asociación científica, cuyas señas de identidad incluyen compromiso con la sociedad, independencia, defensa de un modelo de atención público, una práctica profesional basada en principios técnico-científicos y éticos y respetuosa con los derechos de los ciudadanos, es nuestra obligación ética oponernos frontalmente a su contenido.

La interrupción voluntaria de embarazo (IVE) está incluida entre los Derechos de la Salud Sexual y Reproductiva (SSR). Se estima que cada año se interrumpen unos 45 millones de embarazos en el mundo y unos 19 millones de esos abortos son peligrosos. El $40 \%$ del conjunto de los abortos peligrosos se da en jóvenes con edades comprendidas entre los 15 y los 24 años. Según las estimaciones, los abortos peligrosos se cobran cada año la vida de 68.000 mujeres, lo que representa un $13 \%$ del total de defunciones relacionadas con el embarazo. Además, llevan asociada una considerable carga de morbilidad: los estudios indican, por ejemplo, que de cada cinco mujeres que se someten a abortos peligrosos, al menos una padece infecciones del aparato reproductor como resultado de ello; en algunos casos, se trata de infecciones graves que causan esterilidad ${ }^{1}$. En esta línea se entiende que las interrupciones del embarazo

1 Organización Mundial de la Salud, 2004. "Estrategia de Salud Reproductiva para Asegurar el Avance hacia la Consecución de los Objetivos y las Metas Internacionales de Desarrollo". 
inseguras son un grave problema de salud pública. En algunos países, incluso, en los casos de embarazos producto de violaciones se niega el derecho a una interrupción voluntaria del embarazo. En estos países con grandes restricciones en derechos de SSR la Sociedad Civil Organizada precisa desarrollar redes y plataformas para la promoción de los servicios de salud sexual y reproductiva encaminadas a eliminar las barreras que impiden el acceso a la interrupción voluntaria del embarazo en condiciones seguras, por medio de estrategias de información, derivación y acompañamiento.

En España, el actual "Anteproyecto de Ley Orgánica para la protección de la vida del concebido y de los derechos de la mujer embarazada" aprobado el pasado mes de diciembre, por el Consejo de Ministros introduce importantes novedades sobre la ley actualmente en vigor. En términos generales supone un cambio de la ley de plazos por otra de supuestos, más restrictiva incluso que la de 1985 lo que no sitúa, desde la vanguardia de los derechos de las mujeres en éste ámbito, lograda con la ley de plazos del 2010, en el furgón de cola de los países menos respetuosos con la voluntad de las mujeres. Supone una regresión que pone en precario los derechos de las mujeres, estigmatizando sobre todo a las que se encuentran en situación de mayor vulnerabilidad y, por ende, tiene un impacto negativo en toda la sociedad. En el caso de aprobarse, esta ley supondrá un retraso en la realización de las IVEs, sumiendo a la mujer en un verdadero laberinto sanitario administrativo, con el consiguiente aumento del sufrimiento mental, tanto para la mujer como para su familia. $\mathrm{La}$ depresión, la ansiedad, la inseguridad y la culpa traerá ineludiblemente un incremento de cuadros de la esfera depresiva y ansiosa, además de un aumento de los viajes a nuestro entorno próximo (Francia, Portugal), para interrumpir el embarazo en condiciones más civilizadas. Para las mujeres con menos información y recursos económicos y sociales supondrá un aumento de las IVEs en condiciones lamentables y clandestinas, con riesgos graves para su salud.

Es bien sabido que no existen predictores clínicos ni psicopatológicos que evalúen futuribles en relación con cualquier circunstancia vital estresante, con suficiente evidencia científica de lo "importante y grave" del daño que puede causar ni de su permanencia en el tiempo, por tanto evaluar en una mujer sana, que quiere abortar, una futura vulnerabilidad o enfermedad mental no es fiable, si nos atenemos a una práctica científica y ética.

Sin embargo, existen datos que nos orientan sobre el papel de los psiquiatras en las legislaciones españolas anteriores concernientes a la IVE. Desde la aplicación de la ley de 1985 (Ley de supuestos), hasta la promulgación de la nueva en 2010 (Ley de Plazos), un $96,77 \%$ de mujeres que abortaban lo hacían por el supuesto de riesgo psíquico para la madre constatado por un informe emitido por un psiquiatra ${ }^{2}$.

Las intervenciones se realizaron en más de $97 \%$ de los casos en clínicas privadas salvo en 2012 que fue en un $93 \%$. En estadísticas del 2012 un $68 \%$ de IVE se produjeron dentro de las primeras 8 semanas. Fuente: Ministerio de Sanidad. http://www.msssi.gob.es/profesionales/saludPublica/prevPromocion/embarazo/tablas_figuras.h 
EDITORIAL

Tras la ley orgánica 2/2010 (Ley de Salud sexual y reproductiva y la interrupción voluntaria del embarazo) que permitía abortar en las primeras 14 semanas sin que fuera necesario que la mujer argumentara motivos, el $89,58 \%$ de mujeres lo hicieron por decisión propia y sólo en un 7,3\% se argumentó riesgo para su salud.

Estamos plenamente seguros de que en el caso de que se aprobara la ley tal como está configurada, el argumento de "enfermedad mental" aparecerá como causa mayoritaria de las interrupciones del embarazo, ya que con la nueva ley que se propone, $\mathrm{ni}$ siquiera el riesgo psíquico es motivo legal para abortar, como sí lo era en el 1985.

Estos datos estadísticos tan elementales deben ponernos en guardia sobre el dudoso papel que la psiquiatría, realiza cuando se ocupa de tareas que no le corresponden. Puede lograrse fácilmente la perversión de datos epidemiológicos y, lo que es aun más grave, supone que las mujeres, para poder abortar legalmente, deban presentar dos informes psiquiátricos que valoren "un daño psíquico y persistente en el tiempo", prácticamente que sean consideradas como enfermas mentales. Esta etiqueta diagnóstica puede condicionar que, en otra circunstancia vital, por ejemplo en caso de conflicto posterior respecto a la custodia de los hijos, se vuelva a valorar esa vulnerabilidad psíquica, cerrando un círculo infernal contra la mujer. Desde sus orígenes la psiquiatría ha constituido uno de los elementos del poder para dominar a la población mediante medidas de control especialmente en el ámbito de la libertad sexual (hasta 1973 se diagnosticaba que la homosexualidad como una condición patológica).

No faltan desgraciadamente casos de utilización espuria de los psiquiatras, Lo demuestra la participación de algunos psiquiatras prestigiosos en los programas eugenésicos de los nazis, que llevaron a la muerte a miles de discapacitados psíquicos y mentales. O la depuración de la disidencia en la Unión Soviética. Quién sabe si también en la sofisticación de los interrogatorios en Guantánamo u otros agujeros negros del sistema.

De esta manera, la función de los profesionales de la Salud Mental: promover la salud psíquica y las condiciones que la favorecen, prevenir la enfermedad, diagnosticarla, tratarla y acompañarla en alianza con los afectados, se ha pervertido en múltiples ocasiones en aras de utilizarla ideológicamente.

Afortunadamente no estamos en el mismo caso, pero aquellos terribles acontecimientos tendrían que ser suficiente aviso del peligro que tenemos los psiquiatras cuando nos dan un poder que no nos corresponde. Este uso ilegítimo de la psiquiatría posibilita que los sectores más conservadores de la sociedad se amparen, y calmen su mala conciencia, apelando a un supuesto saber científico para justificar la imposición a toda la sociedad, de su moralidad y sus temores: a la homosexualidad, a la libertad de las mujeres, etc. invocando criterios profesionales, pretendida y falsamente científicos. El resultado final es una instrumentalización de los psiquiatras. 
EDITORIAL

En este Anteproyecto, a los psiquiatras se nos confiere el papel de tutores de la voluntad de las mujeres. Coloca a la mujer embarazada en la posición de ceder el control de su cuerpo a terceros, a nosotros los psiquiatras, otorgándonos un poder que no queremos: "el de tutelar en una decisión de relevancia biográfica crucial a personas adultas y competentes, por el simple hecho de ser mujeres, pasando de inmediato a ser consideradas incompetentes o menores de edad". Así, este gobierno condena a las mujeres a ser ciudadanas de segunda, incapaces de ejercer la responsabilidad y su derecho a decidir cuándo, cómo y cuántas veces quiere ser madre.

Como nos recordaba hace varios años Álvaro Múzquiz en un artículo titulado "colaboraciones, escisión y reconstrucción del lugar de la psiquiatría en la política del presente" publicado en en las páginas del Boletín de la AMSM: "En una sociedad en la que la vida es el mayor de sus valores políticos, en que toda política es biopolítica, la medicina y la psiquiatría son las disciplinas políticas por excelencia, en ellas es donde se está haciendo política. Los supuestos problemas técnicos de la psiquiatría son, entonces y sobre todo, problemas políticos". El Ministro Gallardón con su reforma de la ley del aborto o el rescate de concepto de peligrosidad social en el nuevo anteproyecto de ley del Código Penal nos recuerda este lugar central de nuestras práctica.

Este anteproyecto nos pone, también, en el dilema ético de la objeción de conciencia, que muchos reclaman para no ser instrumentalizados ni mentir en los futuros informes: tener que objetar y abandonar a la mujer en un trance vital estresante o hacer algo que no se ajusta a los criterios éticos de la práctica de la psiquiatría y reconocer un problema mental que no existe para que una mujer pueda abortar. Los pactos de objeción de conciencia que niegan actividad asistencial a aquellos cuya moral, etnia o religión no nos gusta no buscan proteger una parte frágil de los facultativos, inherente a ellos por ser personas; buscan otorgar a los médicos una categoría superior; buscan convertirles en ciudadanos de primera con potestad para regular los derechos de los ciudadanos de segunda, es decir, los usuarios. Una licenciatura en medicina, un título de especialista en psiquiatría no nos hacen ni mejores, ni expertos para decidir por las mujeres qué es moralmente adecuado y qué no lo es; cuándo una mujer desea o puede tener un hijo y cuándo no. Los psiquiatras no deseamos esa autoridad a la hora del aborto. Son las mujeres quienes deben decidir libremente sobre su embarazo y la ley debería establecerlo así sin disimulos, en vez de dejarlo en manos del psiquiatra, que no es guardián de la conciencia, de legisladores o sacerdotes. Cada uno a lo suyo y cada cual en su faena. Los psiquiatras con la nuestra ya tenemos bastante. 